\title{
KEANEKARAGAMAN JENIS IKAN DI SUNGAI EMBALOH DESA BANUA UJUNG KECAMATAN EMBALOH HULU KABUPATEN KAPUAS HULU
}

\author{
(Fish Species Diversity In Embaloh River, Banua Ujung Village, Embaloh Hulu Sub District, \\ Kapuas Hulu District)
}

\author{
Odilo Noplantino Ajai, M. Sofwan Anwari, Dirhamsyah \\ Fakultas Kehutanan Universitas Tanjungpura, Jl. Daya Nasional Pontianak 78124 \\ Email: odiloajai@gmail.com
}

\begin{abstract}
The condition of Embaloh River is still well maintained, with clear water and a large variety of fishes. This is because the forest around Embaloh River is still dense; there is no deforestation, mining, and palm oil garden. In such a condition, the river is capable of maintaining a large variety of fishes that have not listed yet. Therefore, this research has the purpose of studying the variety of fishes in Embaloh River, and also to categorize the fishes based on their benefits, whether as decorative fishes, to be eaten, or even as a decorative fish and also to be eaten. The research was conducted on the Embaloh River, Banua Ujung Village, Embaloh Hulu District, Kapuas Hulu Regency. Research Data is obtained by the use of fishing equipment such as mesh, Bubu, Sauk, trawler, burst, and Talom. The method of research using the survey method, the selection of observation stations conducted with (purposive sampling) based on consideration of environmental conditions of the water. This location is made 3 (three) stations on the Embaloh River and 1 (one) station is on the lake (oxbow) called Lake Loane. Lake Loane is a stream of the Embaloh River Moreover, fish of species taken from Embaloh River and Loane Lake, which water from Embaloh River flows to, consist of several families of fish; Cobitidae (1 species), Cyprinidae (13 species), Elopidae (1 species), Grynocheilidae (1 species), Helostomatidae (1 species), Osphronemidae (2 species), Polynemidae (1 species), Pristolepididae (1 species), Sisoridae (1 species), and Syngnathidae (1 species).
\end{abstract}

Keywords: Banua Ujung Village, Embaloh River, Fish Species Diversity, Loane Lake.

\section{PENDAHULUAN}

Luas perairan umum di Propinsi Kalimantan Barat mencapai dua juta hektar yang terdiri atas danau rawa dan sungai. Salah satunya adalah Sungai Kapuas yang merupakan sungai terbesar di Kalimantan Barat dan terpanjang di Indonesia, yaitu $1.080 \mathrm{~km}$ (Sutikno, 1981). Daerah Aliran Sungai Kapuas mempunyai tipe ekologi yang sangat komplek, namun secara garis besar ada tiga tipe yang penting yaitu; 1) tipe perairan berarus deras sampai sedang, 2) tipe perairan yang merupakan rawa banjiran, 3) tipe perairan yang masih dipengaruhi oleh pasang surut air laut (Utomo et al., 1991).

Kalimantan termasuk salah satu pulau terbesar di Indonesia bahkan dunia. Luas keseluruhan pulau Kalimantan adalah $736.000 \mathrm{~km}^{2}$. Kondisi geografis yang berbukit mengakibatkan Kalimantan memiliki banyak aliran sungai. Sungai mempunyai potensi dan peranan penting bagi kelangsungan aktivitas seluruh mahluk hidup. Menurut Kottelat et al (1993) jenis ikan di Kalimantan berjumlah 
sekitar 394 jenis dengan 149 jenis endemik (38\%), Sumatera 272 jenis dengan 30 jenis endemik (11\%), Jawa berjumlah 132 jenis dengan 52 jenis endemik (29\%) dan Sulawesi berjumlah 68 jenis dengan 52 jenis endemik (76\%).

Nelson dalam Haryono (2009) mengatakan bahwa sampai saat ini jumlah ikan di dunia berdasarkan identifikasi sebanyak 24.618 jenis, dan $40 \%$ diantaranya ikan air tawar. Djajadiredja $d k k$ dalam Trijoko dan Pranoto (2006) mengatakan bahwa terdapat kurang lebih 8.500 jenis ikan, dengan jumlah 800 jenis ikan terdapat pada perairan tawar dan payau. Indonesia menempati rangking kedua di dunia setelah Brazil, dan di Asia Indonesia menempati rangking pertama dengan jumlah jenis ikan air tawar terbanyak (Budiman $d k k .$, 2002).

Kondisi Sungai Embaloh masih sangat terjaga dengan keanekaragaman jenis ikan yang tinggi. Hal ini dikarenakan kondisi hutan di sekitar Sungai Embaloh yang masih alami, tidak ada kegiatan penebangan liar, pertambangan ataupun perkebunan sawit. Kerapatan vegetasi yang tinggi di sekitar Sungai Embaloh bukan saja menjadi naungan bagi satwa di darat, tetapi juga menjadi naungan bagi ikan-ikan yang terdapat di hulu sungai. Penelitian ini bertujuan untuk mengkaji keanekaragaman jenis ikan yang ada di Sungai Embaloh, dan juga untuk mendata jenis-jenis ikan yang berpotensi sebagai ikan hias, konsumsi, atau ikan hias sekaligus konsumsi.

\section{BAHAN DAN METODE}

Penelitian dilaksanakan di Sungai Embaloh, Desa Banua Ujung, Kecamatan Embaloh Hulu, Kabupaten Kapuas Hulu.
Penelitian ini dilakukan selama 1 (satu) bulan efektif di lapangan mulai tanggal 6 Juli-6 Agustus 2019. Peralatan yang digunakan dalam penelitian ini adalah Peta Lokasi Penelitian skala 1:250.000, Umpan Ikan, Alat Tangkap Ikan, Sampan (sebagai alat transportasi), Kertas $\mathrm{pH}$ (untuk menguji kualitas air), Thally Sheet, Buku Identifikasi Ikan (Kottelat $d k k$, 1993).

Penelitian ini dilaksanakan di Sungai Embaloh dan Danau Loane. Penentuan titik sampling dilakuan dengan Purposive Sampling, yaitu menyesuaikan dengan daerah yang dimana terdapat banyak ikan nya seperti lubuk sungai dan tepian sungai setiap stasiun. Lokasi ini dibuat 3 (tiga) stasiun dan 1 (satu) stasiun berada di danau (oxbow). Pengambilan sampel dilakukan 3 (tiga) kali pengulangan pada siang dan malam hari.

Pengambilan sampel ikan dilakukan dengan metode hasil tangkap per unit usaha (Rachmatika dan Haryono, 1996) yaitu dengan menggunakan alat tangkap jala dengan 10 kali tebaran setiap stasiun, dengan 2 utas pukat (mata jaring 1 inci dan 3.5 inci) secara vertikal pada tiga stasiun yang berada di sungai dan secara horizontal pada satu stasiun yang berada di danau, 1 buah seruak di tepian sungai setiap stasiun, 1 buah bubu di tepian sungai setiap stasiun, dan 2 talom di tepian sungai setiap stasiun. Pemasangan Seruak dan bubu dilakukan sehari sebelum pengambilan sampel di stasiun. Penggunaan sauk dilakukan ketika berada di pinggiran sungai. Sampel ikan yang tertangkap pada setiap lokasi dicatat jenis dan jumlahnya, setiap jenis ikan dibuat dokumentasinya, identifikasi dan 
determinasi mengacu kepada buku identifikasi (Kottelat $d k k$., 1993).

Analisis data dilakukan dengan menghitung Indeks Dominansi, Indeks Keanekaragaman, Indeks Kemerataan, Indeks Kekayaan, Indeks Kesamaan serta Indeks Biologi.

\section{HASIL DAN PEMBAHASAN}

Jumlah ikan yang ditemukan pada kawasan Sungai Embaloh dan Danau
Loane sebanyak 708 individu, yang tergolong dalam 23 jenis ikan dalam 10 famili. Sungai Embaloh terdapat 540 individu yang tergolong dalam 19 jenis ikan dan Danau Loane terdapat 168 individu yang tergolong dalam 7 jenis ikan. Jenis ikan yang ditemukan di Sungai Embaloh dan Danau Loane disajikan pada Tabel 1 dan Tabel 2.

Tabel 1. Daftar Jenis Ikan Air Tawar Yang Ditemukan di Sungai Embaloh (List Of Freswater Fish Species Found On The Embaloh River).

\begin{tabular}{llll}
\hline No & Famili & Nama Ikan (ilmiah) & $\begin{array}{l}\text { Nama Ikan } \\
\text { (daerah) }\end{array}$ \\
\hline 1 & Cobitidae & Botia hymenophysa & Paset \\
2 & Cyprinidae & Barbodes gonionotus & Joan \\
3 & Cyprinidae & Amblyrhynchichthys truncates & Toalang \\
4 & Cyprinidae & Barbodes collingwoodi & Sare \\
5 & Cyprinidae & Barbichthys laevis & Kungkum \\
6 & Cyprinidae & Parachela hypophthalmus & Salong Daun Bulo' \\
7 & Cyprinidae & Osteochilus hasseltii & Paloh \\
8 & Cyprinidae & Rasborichthys helfrichii & Ampungan \\
9 & Cyprinidae & Macrochrichthys macrochirus & Babaja' \\
10 & Cyprinidae & Tor tambra & Semah \\
11 & Cyprindae & Barbodes schwanenfeldii & Tengadak \\
12 & Cyprinidae & Hampala macrolepidota & Arungan \\
13 & Cyprinidae & Luciosoma trinema & Limbunga \\
14 & Grynocheilidae & Gyrinocheilus pustulosus & Binkus \\
15 & Osphronemidae & Osphronemus septemfasciatus & Kali Dadara' \\
16 & Polynemidae & Polystonemus multifilis & Kadangkang \\
17 & Pristolepididae & Pristolepis fasciata & Limpatong \\
18 & Sisoridae & Bagarius yarrelli & Tangkudau \\
19 & Syngnathidae & Microphis brachyurus & Panjuluk Talinga \\
& & & Burawing \\
\hline
\end{tabular}

Jenis ikan air tawar yang didapat di Sungai Embaloh didominasi oleh famili Cyrpinidae berjumlah 12 jenis, kemudian diikuti oleh famili Cobitidae, Grynocheilidae, Osphronemidae, Polynemidae, Pristolepididae, Sisoridae, Syngnathidae berjumlah masing-masing 1 jenis. Menurut Kottelat et al (1993) bahwa jenis ikan Cyprinidae merupakan penghuni utama yang paling besar jumlah populasinya untuk beberapa sungai di Kalimantan selain jenis Bagridae, Balitoridae, Belontiidae, dan Siluridae. Jumlah jenis ikan yang terkumpul di Sungai Embaloh Hulu pada dasarnya tergolong kecil bila 
dibandingkan dengan hasil penelitian yang dilakukan oleh Yustina (1998) di Sungai Rangau Propinsi Riau yang berjumlah 70 jenis.

Ikan yang berpotensi sebagai ikan konsumsi yang berasal dari famili Cyprinidae antara lain: Kungkum (Barbichthys laevis), Joan (Barbodes gonionotus), Sare (Barbodes collingwoodi), Saloang Daun Bulo' (Parachela hypophthalmus), Paloh (Osteochilus hasseltii), Ampungan (Rasborichthys helfrichii), Tengadak (Barbodes schwanenfeldii), dan Limbunga (Luciosoma trinema). Ikan yang berpotensi sebagai ikan konsumsi selain dari famili Cyprinidae antara lain: Grynocheilidae (Binkus/ Gyrinocheilus pustulosus), Polynemidae (Kadangkang/ Polystonemus multifilis), Pristolepididae (Limpatong/ Pristolepis fasciata), dan Sisoridae (Tangkudau/ Bagarius yarrelli).

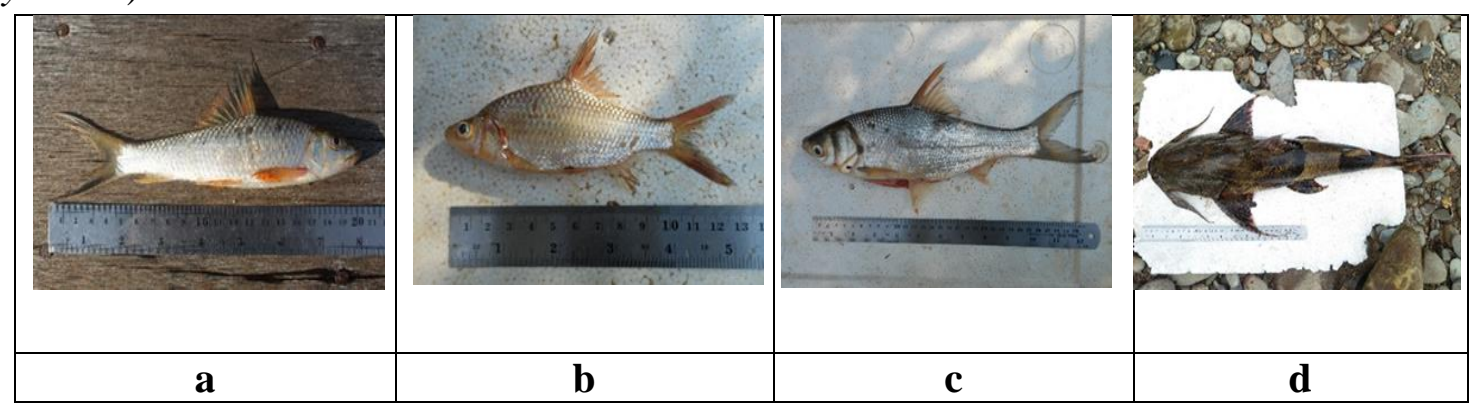

Gambar 1. Jenis Ikan Konsumsi. (a). Barbichthys laevis, (b). Barbodes gonionotus, (c). Barbodes collingwoodi, (d). Bagarius yarelli.
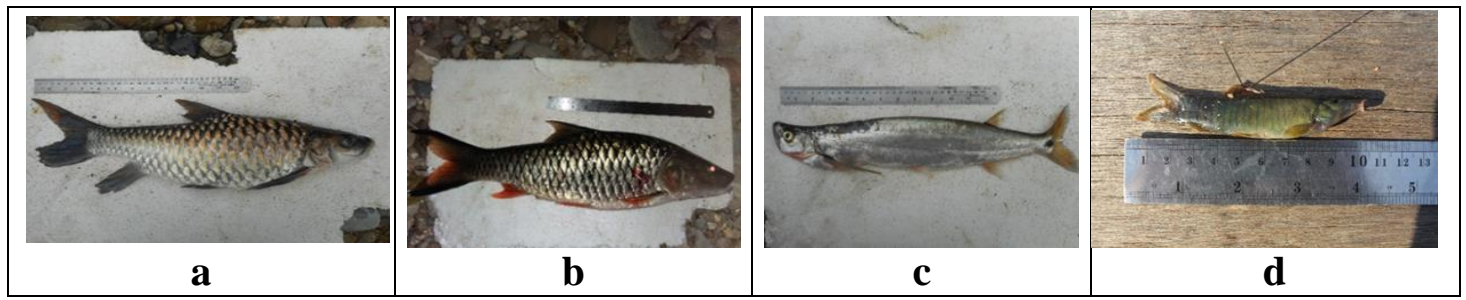

Gambar 2. Jenis Ikan Hias sekaligus Konsumsi. (a). Tor tambra, (b). Hampala macrolepidota, (c). Macrochrichthys macrochirus, (d). Botia hymenophysa. 
Tabel 2. Daftar Jenis Ikan Air Tawar Yang Ditemukan di Danau Loane (List Of Freshwater Fish Species Found On The Loane Lake).

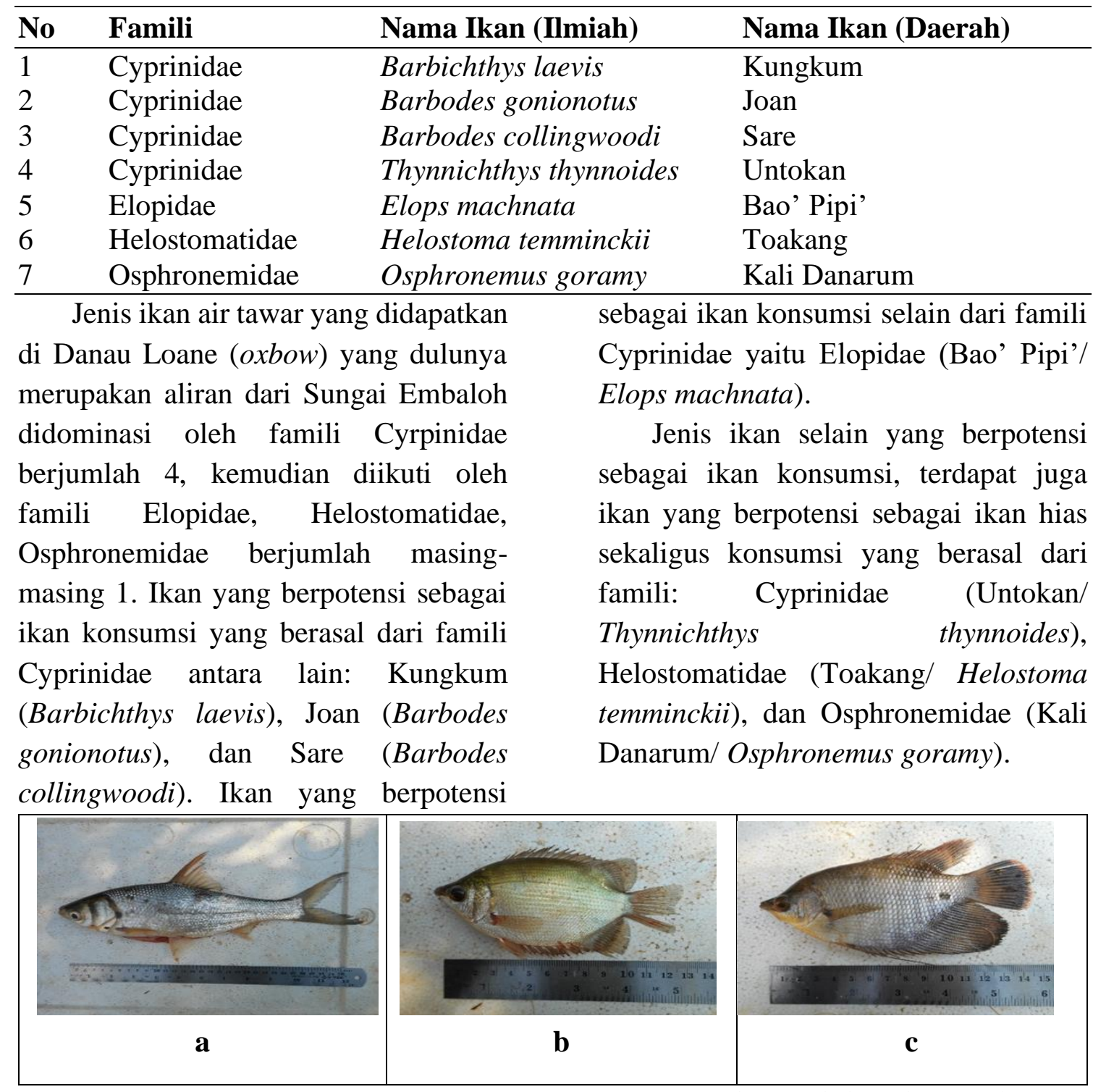

Gambar 3. Jenis Ikan Hias Sekaligus Konsumsi. (a). Thynnichthys thynnoides, (b). Helostoma temminckii, (c). Osphronemus goramy. 
Tabel 3. Indeks Dominan, Indeks Keanekaragaman Jenis, Indeks Kemerataan Jenis, dan Indeks Kekayaan Jenis Ikan Air Tawar di Sungai Embaloh dan Danau Loane (Dominand Index, Species Diversity Index, Species Evennes Index, Species Richness Index Of Freshwater Fish In Embaloh River and Loane Lake)

\begin{tabular}{lcc}
\hline Indeks & Sungai Embaloh & Danau Loane \\
\hline Dominan (C) & 0.119417 & 0.219813 \\
Keanekaragaman Jenis (H') & 2.381870 & 1.638669 \\
Kemerataan Jenis (E) & 0.808939 & 0.842109 \\
Kekayaan Jenis (R) & 2.8610 & 1.1710 \\
\hline
\end{tabular}

Indeks dominansi ikan air tawar secara keseluruhan pada Sungai Embaloh dan Danau Loane adalah $(\mathrm{C})=$ 0.125427 yang berarti tidak terdapat jenis yang mendominansi jenis lainnya karena tidak ada jumlah individu suatu jenis ikan yang melimpah. Nilai indeks keanekaragaman jenis secara keseluruhan adalah $\left(\mathrm{H}^{\prime}\right)=2.434511$ yang menunjukan keanekaragaman jenis ikan pada Sungai Embaloh dan Danau Loane dalam kriteria sedang karena jumlah jenis yang terdapat cukup banyak. Indeks Kemerataan jenis $(E)=0.776436$ yang berarti kemerataan jenisnya rendah, dan nilai kekayaan jenis ikan air tawar pada Sungai Embaloh dan Danau Loane adalah $(\mathrm{R})=3.3524$ yang berarti kekayaan jenisnya sedang.

Berdasarkan hasil perhitungan indeks dominansi jenis ikan air tawar, diketahui bahwa pada setiap perairan memiliki dominansi yang berbeda. Nilai indeks dominansi tertinggi terdapat pada Danau Loane dengan nilai sebesar 0.219813 karena pada Danau Loane (oxbow) terdapat ikan yang hidupnya secara mengelompok dan faktor lingkungan perairan yang tertutup membuat ikan sulit untuk keluar menuju aliran sungai utama menyebabkan ikan tertahan di danau. Indeks dominansi Sungai Embaloh sebesar 0.119417 yang memiliki nilai indeks dominansi terendah dibandingkan dengan Danau Loane karena pada Sungai Embaloh ini terdapat jumlah jenis yang melimpah tetapi jenis individu yang didapatkan hanya sedikit. Menurut Ferianita (2007), kisaran nilai indeks dominan adalah 0 1 apabila nilai $\mathrm{C}=0$ berarti tidak terdapat jenis yang mendominasi jenis lainnya dan apabila nilai $\mathrm{C}=1$ berarti terdapat jenis yang mendominasi jenis lainnya, sehingga dapat diketahui bahwa Sungai Embaloh dan Danau Loane menunjukkan tidak terdapat jenis yang mendominasi jenis lainnya. Diketahui bahwa indeks dominansi di Danau Loane > Sungai Embaloh karena jenis ikan di Danau Loane < Sungai Embaloh, maka nilai C pada Danau Loane lebih tinggi dibandingkan Sungai Embaloh, hal ini dikarenakan nilai indeks dominannya adalah 0.219813 - 0.119417 .

Kriteria indeks keanekaragaman jenis menurut Ferianita (2007), yaitu jika nilai $H^{\prime}<1$ berarti keanekaragaman jenis rendah, jika nilai $1<\mathrm{H}^{\prime}<3$ berarti keanekaragaman sedang dan jika nilai $\mathrm{H}^{\prime}$ $>3$ berarti keanekaragaman jenis tinggi. Berdasarkan hasil tersebut dapat 
diketahui bahwa pada Sungai Embaloh Hulu memiliki indeks keanekaragaman sedang dengan nilai (H') sebesar 2.381870 dan pada Danau Loane memiliki nilai indeks keanekaragaman jenis rendah yaitu dengan nilai ( $\left.\mathrm{H}^{\prime}\right)$ sebesar $\quad 1.638669$. Indeks keanekaragaman jenis ikan air tawar yang tertinggi terdapat pada Sungai Embaloh dengan nilai $\left(\mathrm{H}^{\prime}\right)=2.381870$ yang berarti keanekaragaman jenisnya sedang, serta di Danau Loane memiliki indeks keanekaragaman jenis $\left(\mathrm{H}^{\prime}\right)=$ 1.638669 yang berarti keanekaragaman jenisnya rendah. Diketahui bahwa indeks keanekaragaman jenis di Sungai Embaloh > Danau Loane karena jumlah jenisnya lebih banyak dibandingkan Danau Loane.

Indeks kemerataan jenis ikan air tawar yang tertinggi terdapat pada Danau Loane dengan nilai $(E)=0.842109$ yang menunjukan kemerataan jenis rendah, sedangkan pada Sungai Embaloh memiliki nilai $(\mathrm{E})=0.808939$ yang berarti kemerataan jenisnya rendah. Terdapat perbedaan yang tidak terlalu jauh pada indeks kemerataan jenis antara Sungai Embaloh dan Danau Loane. Dapat diketahui kisaran indeks kemerataan jenis adalah $0-1$, jika nilai $\mathrm{E}=0$ berarti kemerataan jenis rendah, dan jika nilai $\mathrm{E}=1$ berarti kemerataan antar jenis relatif merata/sama (Ferianita, 2007). Diketahui bahwa indeks kemerataan jenis antara Sungai Embaloh dan Danau Loane terbilang relatif merata.

Berdasarkan perhitungan indeks kekayaan jenis (R) pada Sungai Embaloh dan Danau Loane, pada Sungai Embaloh dengan nilai indeks kekayaan jenis (R) sebesar 2.8610, dan pada Danau Loane memiliki nilai indeks kekayaan jenis (R) sebesar 1.1710, diketahui bahwa indeks kekayaan jenis di Sungai Embaloh > Danau Loane karena kekayaan jenis di Sungai Embaloh lebih banyak dibandingkan Danau Loane.

Berdasarkan perhitungan indeks kesamaan jenis (IS) di Sungai Embaloh dan Danau Loane pada siang hari (diurnal), diketahui bahwa nilai (IS)= $35.00 \%$ yang berarti kriteria jumlah jenis antara Sungai Embaloh dan Danau Loane tergolong rendah $<50 \%$ dan terdapat perbedaan jenis. Berdasarkan perhitungan indeks kesamaan jenis (IS) di Sungai Embaloh pada malam hari (nocturnal), diketahui bahwa nilai (IS)= $35.29 \%$ yang berarti kriteria jumlah jenis antara Sungai Embaloh dan Danau Loane tergolong rendah $<50 \%$ dan terdapat perbedaan jenis.

Perhitungan Kesamaan Jenis antara Sungai Embaloh dan Danau Loane baik itu pada saat siang hari ataupun malam hari terdapat perbedaan jenis yang sangat nyata, dikarenakan kondisi di Sungai Embaloh yang merupakan perairan terbuka, memiliki kualitas air yang bagus, serta ketersediaan pakan sangat melimpah bagi ikan, sedangkan pada Danau Loane yang merupakan perairan tertutup memiki kondisi air yang kurang bagus, serta ketersediaan pakan terbatas bagi ikan. Perbedaan kondisi Sungai Embaloh dan Danau Loane dalam segi kualitas air dan ketersediaan pakan 
menjadi faktor dalam perbedaan jenis ikan.

\section{KESIMPULAN}

Sebanyak 708 individu yang didapat tergolong dalam 23 jenis dalam 10 famili, 540 di Sungai Embaloh dan 168 di Danau Loane, satu diantaranya ikan purba yaitu Bagarius yarrelli. Famili Cyprinidae yang terbanyak dari familifamili lainnya ada 13 jenis ikan. Nilai indeks keanekaragaman jenis di Sungai Embaloh menunjukan keanekaragaman jenis sedang, sedangkan indeks keanekaragaman pada Danau Loane yang menunjukan keanekaragaman jenisnya rendah.

\section{DAFTAR PUSTAKA}

Budiman A, Arief AJ, \& Tjakrawidjaya AH. (2002). Peran Museum Zoologi Dalam Penelitian dan Konservasi Keanekaragaman Hayati (Ikan). Jurnal Iktiologi Indonesia, 2(2), 51-55.

Ferianita FM. (2007). Metode Sampling Bioekologi. Jakarta: Bumi Aksara.

Haryono. (2009). Komunitas Ikan di Perairan Bukit Sapathawung Kawasan Pegunungan Muller Kalimantan Tengah. Jurnal Penelitian Bidang Zoologi, Pusat Penelitian Biologi, Bogor, 18(1). 21-32.

Kottelat M, Anthony JW, Sri NK \& Soetikno W. (1993). Freshwater Fishes of Western Indonesia and Sulawesi. Jakarta:Periplus Editios (HK), 2(2). 118-125.

Rachmatika I, dan Haryono. (1996). Ichtiofauna Taman Nasional
Bentuang Karimun. Makalah Lokakarya"Keterpaduan antara Konservasi dan Pembangunan kawasan Taman Nasional Bentuang Karimun di Perbatasan Kalimantan Barat dan Malaysia". Pontianak, 13-14 November 1996, 1(1). 19-26.

Sutikno. (1981). Status perikanan perairan umum Kalimantan Barat. Prosiding Seminar Perairan Umum. Puslitbang Perikanan Jakarta, 107-114.

Trijoko. Pranoto, S. (2006). Keanekaragaman Jenis Ikan Di Sepanjang Aliran Sungai Opak Daerah Istimewa Yogyakarta. Prosiding Seminar Nasional Ikan IV. Jatiluhur, 29-30 Agustus 2006. Hlm. 293-298.

Utomo AD, Z Nasution., MF Sukadi. (1991). Potensi Sumberdaya Perikanan DAS Kapuas Kalimantan Barat. Prosiding TKI Pengelolaan Sungai dan Perairan Umum Bagi Perikanan. Puslitbang Perikanan Jakarta. Pros. Puslitbangkan/ No 22/ 1992. 67-80.

Utomo AD, dan Asyari. (1999). Peran Ekosistem Hutan Rawa Air Tawar Bagi Kelestarian Sumberdaya Perikanan di Sungai Kapuas Kalimantan Barat. Jurnal Penelitian Perikanan Indonesia. Puslitbang Perikanan Jakarta, 3(5). 277-286.

Yustina. (1998). Keanekaragaman dan Distribusi Ikan di Sepanjang Perairan Sungai Rangau Propinsi Riau. Tesis. ITB: Bandung. 